\title{
我国高性能高分子复合材料发展现状与展望
}

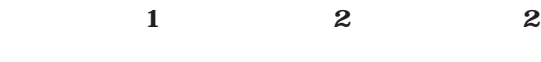 \\ （1. 北京化工大学有机无机复合材料国家重点实验室，北京 100029；2. 中国石油化工股份有限公司 \\ 上海石油化工研究院，上海 201208）
}

摘要: 高性能高分子复合材料因其优异的综合性能, 成为国防与国民经济建设不可或缺的战略性关键材料, 已在航空、航天、 风力发电、轨道交通、汽车等领域进行应用, 发展前景广阔。本文分析了我国发展高性能高分子复合材料的宏观需求, 综述 了高性能高分子复合材料中碳纤维、芳纶、高性能玻璃纤维等纤维增强体以及复合材料用高分子树脂基体如环氧树脂、酚醛 树脂、特种树脂的发展现状及特点, 研判了高性能高分子复合材料发展存在的问题以及今后发展的目标与任务。研究发现, 碳纤维领域初步形成了从关键技术研发到工程化生产的产业化体系, 材料向高性能和低成本双向发展; 对位芳纶产业化初步 成功; 玻璃纤维则保持低速扩张; 高性能高分子复合材料树脂基体产业则面临严峻的发展形势。基于发展需求, 从注重自主 创新、坚持需求牵引、重视产业链建设、加强人才培养与支持产业创新建设等方面提出了发展建议, 以期为我国高性能高分 子复合材料的发展提供参考借鉴。

关键词: 高性能纤维; 高分子树脂基体; 复合材料

中图分类号: TQ343, TQ31 文献标识码: A

\section{Development and Prospect of High Performance Polymer Composites in China}

\section{Cao Weiyu ${ }^{1}$, Yang Xueping ${ }^{2}$, Zhang Ousheng ${ }^{2}$}

(1. State Key Laboratory of Organic-Inorganic Composites, Beijing University of Chemical Technology, Beijing 100029, China; 2. Shanghai Research Institute of Petrochemical Technology, China Petroleum and Chemical Corporation, Shanghai 201208, China)

\begin{abstract}
High performance polymer composites have become an indispensable strategic material for national defense and economic development due to their excellent comprehensive properties. They have broad prospects for development since they have been widely applied in various fields such as aerospace, wind power generation, rail transit, and automobile. The macro development demand of China for high performance polymer composites is analyzed in this paper. The current status and characteristics of fiber reinforcement such as carbon fiber, aramid fiber, and high performance glass fiber as well as polymer resin matrix materials such as epoxy, phenolic resin, and special resin is reviewed. The existing problems and developing objective are also proposed. Specifically, an industrialization system including key technology research and engineering application for the carbon fiber has been established, allowing the carbon fiber industry to develop toward high performance and low cost. The industrial production of para-aramid fiber is preliminarily realized and the glass fiber industry has maintained a stable growth. However, the resin matrix materials for high performance polymer
\end{abstract}

收稿日期 : 2020-07-12; 修回日期 : 2020-08-21

通讯作者: 曹维宇, 北京化工大学有机无机复合材料国家重点实验室研究员, 研究方向为高性能纤维及复合材料; E-mail: caowy@mail.buct.edu.cn

资助项目：中国工程院咨询项目“新材料强国 2035 战略研究” (2018-ZD-03)

本刊网址：www.engineering.org.cn/ch/journal/sscae 
composites face a severe situation. Furthermore, suggestions are proposed based on the demand of development from the viewpoint of independent innovation, demand orientation, construction of industrial chain, personnel training, and industrial innovation, hoping to provide an effective reference for the development of high performance polymer composites in China.

Keywords: high performance fiber; polymer resin matrix; composites

\section{一、前言}

高性能高分子复合材料指采用碳纤维、芳纶、 玻璃纤维等纤维增强环氧树脂、双马来酰亚胺树脂 等高性能树脂为代表的一类材料, 综合性能优异, 是国防与国民经济建设不可或缺的战略性关键材 料。高性能高分子复合材料作为高端装备的主要物 质基础, 在航天、航空等武器装备的轻质结构、烧 蚀防热部件上发挥着不可替代的作用，如应用于高 超声速飞行器、临近空间飞行器以及深空探测飞行 器等新一代武器装备和重大科技工程中。同时, 高 性能高分子复合材料在以高端工业制造、轨道交通、 清洁能源等为代表的国民经济各重大领域也有着广 泛应用。

目前, 国际上在高性能高分子复合材料领域已 经形成了相对较为成熟的产业并持续稳定发展。在 增强体材料方面, 碳纤维作为先进复合材料最重要 的增强体，面向应用需求的特种化或高性能化技术 以及大规模工业级低成本技术已成为研究热点。在 对位芳纶方面，产业链建设越来越受到重视，技术 一体化趋势愈发明显, 新兴应用领域不断涌现。玻 璃纤维产业已形成从纤维、制品到复合材料的完整 产业链。树脂基体的发展已进入有序稳定期。在复 合材料制造技术上，自动化制造技术日趋普遍，航 空和航天复合材料技术进入成熟期，风力发电和 汽车领域的应用为碳纤维复合材料产业注入新的 活力, 热塑性复合材料在轨道交通和汽车产业中 的应用前景广阔。

近年来, 随着航空、航天、风力发电、轨道交 通、汽车、高压容器等产业对高性能高分子复合材 料需求的进一步增长, 我国高性能高分子复合材料 产业已初具规模，应用领域和产能持续扩大，逐渐 向低成本、高性能方向发展。与国外先进水平相比, 我国高性能高分子复合材料产业发展仍存在不小的 差距。为此, 本文在梳理我国高性能高分子复合材 料中各种纤维增强体和树脂基体的产业发展现状与
态势特点的基础上，研判我国复合材料的制造及应 用水平, 分析现阶段存在的问题以及与国际先进水 平形成差距的原因, 最后, 提出我国高性能高分子 复合材料的未来发展方向与对策建议。

\section{二、我国高性能高分子复合材料宏观需求 分析}

高性能高分子复合材料是国防与国民经济建设 不可或缺的战略性关键基础材料，也是《中国制 造 2025》中诸多重点领域发展的材料基础。随着 我国国家战略的转型和国民经济发展新思路的提 出, 对高性能高分子复合材料的发展与应用提出 了迫切需求。

1. 高性能高分子复合材料是实现国家安全领域 支撑保障需求的关键基础材料

随着我国国家创新驱动发展战略的实施, 以航 天强国、航空强国、海洋强国为主要途径的强国策 略成为国之根本。战略导弹、新型装甲及船舶、大 型飞机、新一代战机以及卫星的研发对高性能、多 功能、结构功能一体化的高性能先进复合材料的需 求旺盛，关键复合材料和结构制件成为制约国家重 大安全工程任务完成的瓶颈。例如, 战略战术导 弹、航空发动机热端部件、高超声速飞行器等对 $\mathrm{T} 800$ 以上级碳纤维复合材料的需求迫切; 国产大 型飞机、先进卫星和探月工程项目的实施需要高强 中模、超高强高模碳纤维及其复合材料进行保障。

2. 高性能高分子复合材料是引领技术升级的关 键材料

在航空和航天装备、海洋工程装备及高技术船 舶、先进轨道交通装备、节能与新能源汽车、新材 料产业、电力装备、新一代信息技术产业、高档数 控机床和机器人以及高性能医疗器械等多个重点领 域中, 高性能高分子复合材料是关键基础材料或是 引领技术革命的升级换代材料。如在长度 $40 \mathrm{~m}$ 以 上的风电叶片的梁帽、主梁上使用碳纤维复合材料, 
一方面可以使叶片自重减少 $38 \%$ ，成本降低 $14 \%$; 另一方面提高叶片抗疲劳性能, 提高输出功率, 以 碳纤维为材质可更容易生产出大直径和自适应的风 电叶片。

3. 高性能高分子复合材料是实现我国经济绿色 发展的迫切需求

在能源革新有限的情况下, 节能减排是汽车产 业的重要研究课题, 轻量化是解决问题的关键之一。 先进高分子复合材料具有比模量和比强度高、减重 潜力大、安全性好等突出优点, 是汽车轻量化的最 佳选择。随着复合材料技术的不断进步, 碳纤维复 合材料现已应用于汽车车身、尾翼、底盘、发动机 罩、内饰等。未来汽车产业领域碳纤维需求量的增 长速度将在一定时期内保持在 7\% 左右。

\section{三、我国高性能高分子复合材料的发展现状}

目前, 我国高性能高分子复合材料的发展虽已 取得实质性进展, 但高性能纤维增强体、树脂基体 以及复合材料制备的产业化进程相对缓慢, 部分领 域与世界材料强国相比尚有一定差距。我国高性能 高分子复合材料的发展情况具体如下。

\section{（一）高性能纤维发展各具特点}

1. 碳纤维领域初步形成研发与生产平台, 朝高 性能和低成本方向快速发展

碳纤维是一类碳元素含量在 $90 \%$ 以上的无机 纤维状材料, 其中以聚丙烯腈 (PAN) 纤维为前驱 体制备得到的聚丙烯腈基碳纤维最为重要, 其制 备工艺主要包括丙烯腈 (AN) 聚合物溶液制备、
PAN 原丝制备、PAN 纤维预氧化、PAN 预氧纤 维碳化以及为与树脂复合所进行的表面处理, 若 制备高模量碳纤维还需经过高温石墨化工艺 [1]。 PAN 基碳纤维的生产制备流程, 如图 1 所示。

在国家科技和产业化示范计划的支持下，经过 10 余年的协同攻关, 我国高性能碳纤维制备与应用 技术取得了重大突破 [2]。

(1) 初步建立高性能碳纤维技术与产品体系, 技术水平不断提升

目前, 我国国产碳纤维已初步实现 T300 级 和 T700 级碳纤维的产业化规模生产。具体来看, $\mathrm{T} 300$ 级碳纤维性能基本达到国际水平, 在国防领 域应用渐趋成熟, 在民用领域的应用仍有待开拓; $\mathrm{T} 700$ 级、 T800 级高性能碳纤维突破了干喷湿纺工 艺, 实现了产业化生产; 创新性开发了湿法纺丝 T700 级碳纤维制备工艺, 相关产品已应用于航空领 域; 在实验室条件下, $\mathrm{T} 1100$ 级高性能碳纤维已经 突破关键制备技术。在高模量及高强高模碳纤维领 域, M40 级高模量碳纤维实现了小批量生产, 产能 约为 $300 \mathrm{~kg} / \mathrm{a}$, 并在多个卫星型号上应用; M40J 级 高强高模碳纤维已完成工程化研制, 正在进行应用 考核; M $55 \mathrm{~J}$ 级高强高模碳纤维尚处于工程化研制 阶段, 更高性能的碳纤维品种仍处在关键技术研发 阶段。

（2）已建立一批碳纤维生产企业和研发平台, 国产碳纤维产业格局基本形成

在碳纤维生产企业方面, 我国现有 20 多家碳 纤维企业, 主要分布在山东、江苏、河北和吉林, 国产碳纤维的产业格局基本形成。以威海拓展纤维 有限公司、江苏恒神股份有限公司、中复神鹰碳纤

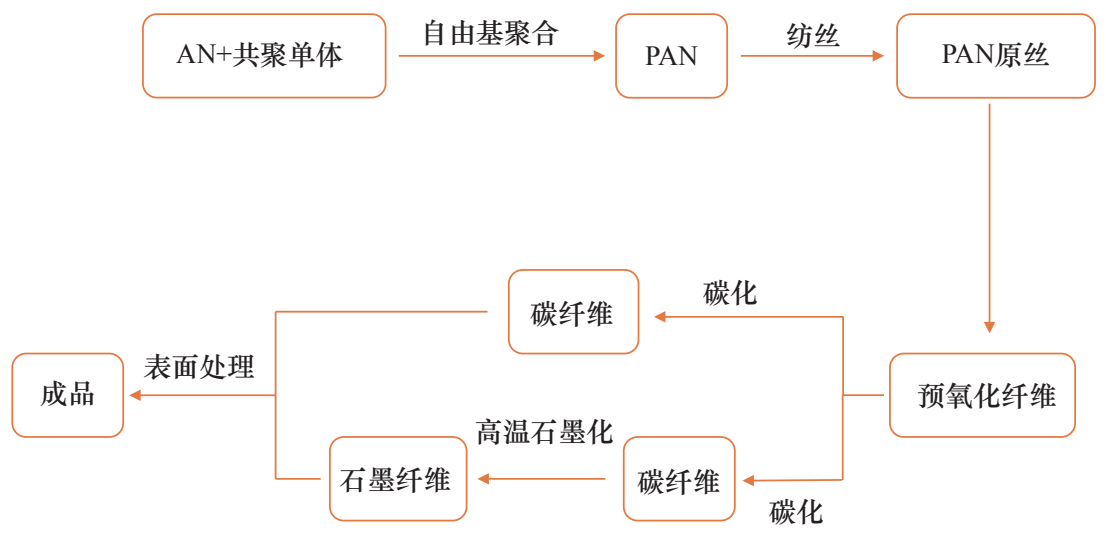

图 1 PAN 基碳纤维生产制备流程 
维有限责任公司、中安信科技有限公司、吉林精功 碳纤维有限公司、中国石化上海石油化工股份有限 公司为代表的 6 家企业建设起 10 条以上的单线产 能达千吨级的生产线，另有 18 家企业建设了几十 吨至几百吨产能的生产线; 同时, 腈纶工业基础的 高强型大丝束碳纤维原丝技术取得突破, 吉林碳谷 碳纤维有限公司建成产能为 $1.5 \times 10^{4} \mathrm{t} / \mathrm{a}$ 的原丝生产 线。2019 年国内碳纤维理论产能达到 $2.6 \times 10^{4} \mathrm{t} / \mathrm{a}$, 有效产能约为 $1.5 \times 10^{4} \mathrm{t} / \mathrm{a}$, 生产的 T300/ T700 级碳 纤维基本满足国防领域的应用需求。碳纤维产业的 产能虽不断增长, 但存在产能大、产量小、开工率 不足等问题。

在平台建设方面, 我国已建设诸多碳纤维科 学技术研究单位以支撑碳纤维产业的国产化发展, 即 1 个国家碳纤维工程技术研究中心、2 个碳纤维 制备技术国家工程实验室、2 个碳纤维复合材料国 家工程实验室、多个国家重点实验室。

2. 对位芳纶产业化成功, 与国际先进水平相比 尚有差距

对位芳纶是对位芳香族聚酰胺纤维家族的重要 成员, 由对苯二甲酰氯与对苯二胺缩聚后制得聚合 物对苯二甲酰对苯二胺, 再经溶液纺丝制得的芳纶 产品。国际上对位芳纶总产能约为 $7.6 \times 10^{4} \mathrm{t} / \mathrm{a}$, 开 工率约为 $70 \%$ $80 \%$ 。我国目前已有 8 家企业建设 了对位芳纶纤维的生产装置, 产能已超过 $7 \times 10^{3} \mathrm{t} / \mathrm{a}$, 具体产能分布情况，如图 2 所示。但全国实际年产 量约为 $1.8 \times 10^{3} \mathrm{t}$, 行业开工率不足 $30 \%$ 。总体来说, 我国对位芳纶产业化水平与国外先进水平的差距较
大，尚未在产业规模、产品质量及应用等方面形成 强有力的竞争格局 [3]。

在平台建设方面, 我国建立了多个芳纶纤维国 家及地方研发与技术平台。例如, 东华大学是纤维 材料改性国家重点实验室依托单位, 华南理工大学 是制浆造纸工程国家重点实验室依托单位, 烟台泰 和新材料股份有限公司是国家芳纶工程中心依托单 位, 中蓝晨光化工研究院有限公司是纤维等高分子 材料多品种、小批量军工材料研发的依托单位。

3. 玻璃纤维产能居世界首位, 保持低速扩张

玻璃纤维是一种优良的功能材料和结构材料。 2016 年全国玻璃纤维的产能约为 $3.8 \times 10^{6} \mathrm{t} / \mathrm{a}$, 占全 球总产能的 $60 \%$ 。2017-2019 年我国玻璃纤维产能 年均复合增长率为 $6.65 \%$, 远高于全球产能年均复 合增长率 $1.70 \%$ 。我国玻璃纤维的年产量从 2005 年 的 $9.5 \times 10^{5} \mathrm{t}$ 增长至 2016 年的 $3.62 \times 10^{6} \mathrm{t}$, 产量年均 复合增长率达到 $12 \%$ 。“十三五” 以来, 玻璃纤维 产能保持低速扩张, 新增产能主要集中在少数企业, 如中国巨石股份有限公司完成了 5 条生产线的改造, 泰山玻璃纤维有限公司新建了池窑生产线, 重庆国 际复合材料股份有限公司投产了冷修线。

\section{（二）复合材料用高性能环氧树脂与酚醛树脂发展 形势严峻}

1. 环氧树脂

环氧树脂是由环氧氯丙烷与双酚 $\mathrm{A}$ 缩聚而成 的热固性树脂，大量用作复合材料的基体树脂，尤 其在航空用复合材料中占主导地位。2016 年世界

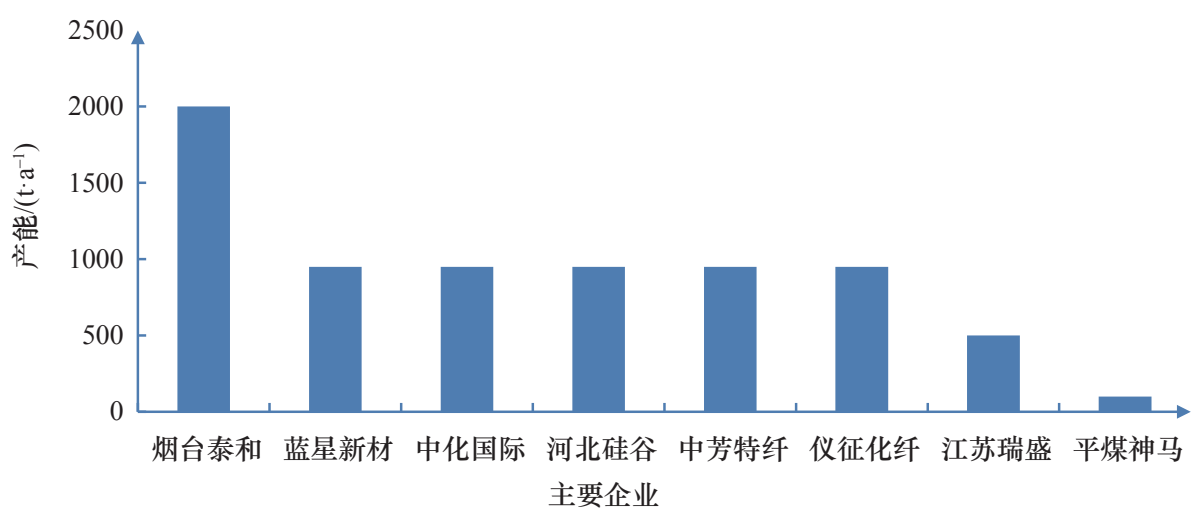

图 22017 年国内对位芳纶纤维主要企业产能情况

注：烟台泰和表示烟台泰和新材料股份有限公司; 蓝星新材表示蓝星化工新材料股份有限公司; 中化国际表示中化国际股份有限公司; 河北硅谷表示河北硅谷 化工有限公司; 中芳特纤表示中芳特纤股份有限公司; 仪征化纤表示仪征化纤股份有限公司; 江苏瑞盛表示江苏瑞盛新材料科技有限公司; 平煤神马表示中国 平煤神马集团。 
环氧树脂总产能约为 $4.62 \times 10^{6} \mathrm{t} / \mathrm{a}$ 。目前, 陶氏化学 公司、南亚塑胶工业股份有限公司和美国迈图特种 化学品公司 3 家企业的环氧树脂产能位居全球产能 前 3 位, 占全球环氧树脂总产能的 $37 \%$ 。我国环氧 树脂产业 2017 年的产能为 $2.3 \times 10^{6} \mathrm{t} / \mathrm{a}$, 占世界总产 能的 $50 \%, 2017$ 年的产量为 $1.2 \times 10^{6} \mathrm{t}$ 。我国生产的 环氧树脂有 $9 \%$ 用于复合材料领域, 其余用于电子 电器、涂料、胶黏剂等领域。

邻甲酚醛环氧树脂是以邻甲酚醛树脂替代双酚 $\mathrm{A}$ 得到的环氧树脂, 比双酚 $\mathrm{A}$ 型环氧树脂具有更高 的环氧值, 固化时能够提供 2.5 倍的交联点, 使复 合材料具有更高的热稳定性、机械强度、电气绝缘 性以及耐化学药品性。目前, 世界邻甲酚醛环氧树 脂市场基本被日本、美国、瑞士等国家的企业垄断, 我国尚不能规模化生产高品质、高纯度的邻甲酚醛 环氧树脂。

通常情况下, 环氧树脂经过固化处理形成网状 立体聚合物, 将复合材料骨材包络在网状体中。根 据固化温度不同, 可以分为室温固化 $\left(20 \sim 30^{\circ} \mathrm{C}\right)$ 、 中温固化 $\left(50 \sim 130^{\circ} \mathrm{C}\right)$ 、高温固化 $\left(130^{\circ} \mathrm{C}\right.$ 以上) 等。 与高温固化相比, 中温固化具有固化温度低、对模 具要求不严、内应力小、尺寸稳定等优点, 具有广 阔的发展空间。为避免固化后的环氧树脂产生韧性 差、脆性强等问题, 需要对其进行增韧改性, 包括 橡胶类弹性体增韧、高性能热塑性聚合物增韧、热 致液晶聚合物增韧等。另外, 还需要对环氧树脂进 行阻燃改性, 近年来无卤阻燃剂得到广泛研究与应 用。分子结构中带有一定量 $\mathrm{N} 、 \mathrm{Si}$ 或 $\mathrm{P}$ 元素的功能 单体, 用作阻然环氧树脂的反应性单体或固化剂, 使树脂复合材料具有较好的阻燃性。目前国内的阻 燃剂生产企业如浙江万盛股份有限公司、江苏雅克 科技股份有限公司等已开始生产有机磷系无卤阻然 剂, 但整体水平及效果与发达国家尚有较大差距。

\section{2. 酚醛树脂}

酚醛树脂, 作为广泛用于复合材料的基体树 脂, 是由酚类化合物 (如苯酚) 和醛类化合物 (如 甲醛) 缩聚而成的热固性树脂, 其中最典型、最重 要的一种酚醛树脂是以苯酚和甲醛缩聚而成的聚合 物。2016 年, 国内约有 200 多家酚醛树脂生产企业, 产能约为 $1.3 \times 10^{6} \mathrm{t} / \mathrm{a}$, 产量约为 $1.02 \times 10^{6} \mathrm{t}$, 居世界 第 1 位。但对于一些高性能酚醛树脂及其复合技术、 铸造技术等, 我国尚未掌握核心关键技术, 亟需提
升国内企业的酚醛树脂改性和铸造水平。

酚醛树脂脆性大、延伸率低, 且其结构上的酚 羟基和亚甲基易氧化。为满足航空、航天及其他高 端领域对酚醛树脂性能的要求, 需进行增韧改性和 耐热改性。在目前已有的改性酚醛树脂中, 嗍酚醛 树脂将 $\mathrm{B}$ 元素引入到酚醛树脂分子结构中, 使酚醛 树脂呈现出高氧指数、低毒、低烟等特点, 是火箭、 航天、导弹、核电站和汽车刹车片等领域急需的重 要材料之一 [4]。

\section{3. 特种树脂基体}

在特种树脂基体方面, 主要有双马来酰亚胺树 脂、氰酸酯树脂、苯并噁嗪树脂等。这些特种树脂 具有良好的耐热性、阻燃性、耐辐射、透波性、电 绝缘性和机械性, 被认为是具有广阔发展前景的一 类热固性聚合物基体树脂, 有望成为环氧树脂的继 任者, 在航空和航天领域得到广泛应用。在美国第 四代战斗机 F-22 中, 复合材料的用量占其结构总 质量的 $24 \%$, 其中 $70 \%$ 为双马树脂基复合材料 [5]。 近 30 年来, 美国、日本、英国、德国等相继对双 马来酰亚胺树脂等特种树脂基体进行了大量改性研 究, 以制备出性能更优异的基体树脂材料。这些特 种树脂在国内均有研发和生产, 与国际先进水平相 比, 在量产规模和产品稳定性方面存在较大差距。

特种树脂基体复合材料作为高性能材料在实际 应用时需解决两大技术难题: (1)通过共聚、共混或 其他方式, 改善树脂的加工性能, 解决固相高温固 化成型带来的脆性大、易断裂等问题; (2)在确保材 料具有足够高的耐热性能、力学性能和机械强度的 同时, 提高韧性, 制备集强度、韧性、耐热性、加 工性等优异性能于一身的复合材料, 满足航空、航 天及其他军工领域的使用要求。

\section{（三）我国复合材料制造及应用水平发展显著}

1. 复合材料技术进入成熟期, 开始较大规模 应用

(1)在航空领域, 复合材料的应用水平得到提升, 用量占比越来越高, 如我国第四代战斗机的复合材 料用量占比为 $25 \%$, 大型运输机复合材料用量占比 为 $15 \%$, 某型直升机复合材料用量占比为 $34 \%$ 。另 外, 我国正在研发阶段的大型客机计划在尾翼、机 翼等结构中使用碳纤维复合材料, 复合材料用量将 占其结构重量的 $15 \%$ 25\%。(2)在航天领域, 随着 
树脂基体性能的不断提高和先进工艺技术的逐步应 用，我国航天结构中复合材料的应用趋势由小尺寸 次承力结构到大尺寸主承力结构方向发展。(3)在兵 器行业弹箭武器上, 主要使用玻璃纤维、碳纤维增 强复合材料等, 其应用范围由非承力和次承力结构 件发展到主承力结构件, 如抗高过载的高内压火箭 发动机壳体、大口径穿甲弹弹托等。据不完全统计, 兵器行业玻璃纤维的年用量已达到上千吨, 碳纤维、 芳纶纤维、聚乙烯纤维的年用量已分别达到 $50 \mathrm{t}$ 、 $70 \mathrm{t} 、 10 \mathrm{t}$ 以上。(4)在民用领域, 风力发电和汽车方 面的复合材料应用为碳纤维复合材料产业注入新的 活力, 热塑性复合材料在轨道交通和汽车产业领域 应用前景广阔。

2. 复合材料自动化制造技术日趋成熟

随着高性能复合材料的广泛应用，复合材料制 造工艺朝多元化、自动化方向快速发展, 复合材料 成型工艺从 2 3 种 (手糊和手工铺贴) 发展到近 10 种 (自动铺放), 2016 年复合材料构件自动化制 造的比例达到 $50 \%, 2020$ 年年底将达到 $65 \%$ 以上。

“十二五” 期间, 我国复合材料自动化制造技 术得到较好发展, 自动铺带、自动铺丝以及预浸料 自动拉挤等先进高效的工艺技术正逐步投入应用， 发展了热熔预浸料生产和热压罐复合材料成型工艺 技术、纤维/布带缠绕成型技术、树脂传递模塑料 成型工艺 (RTM) 成型技术和复合材料结构整体成 型技术，复合材料制造技术体系初步形成，可用于 研制和小批量生产碳纤维、玻璃纤维和芳纶增强高 性能酚醛树脂、环氧树脂、双马来酰亚胺树脂和聚 酰亚胺等多种复合材料, 主要应用于汽车零部件、 轨道交通、通信电力、建筑建材、电力 / 电器、市 政基础设施、新能源开发等领域, 基本满足了航空、 航天、兵器、能源和交通运输领域的需求。

3. 结构功能一体化复合材料技术朝高端化、实 用化方向快速发展, 支撑了高端装备的研制和生产

我国结构功能一体化复合材料技术发展显著, 结构吸波和透波复合材料在新型飞机、导弹、舰船、 地面车辆等领域得到大量应用。结构装甲复合材料 兼具抗弹防护和结构承载功能, 第一代的抗弹/结 构复合材料——高强玻璃纤维增强树脂基复合材 料, 性能已达到美国 MIL-46197A 结构装甲复合材 料标准, 已用于多种装甲装备的舱门舱盖。第二代 的抗弹 / 结构复合材料具备抗弹、承载、隐身等多
功能一体化的特点, 在保持较高刚强度和抗弹性能 的情况下, 在较宽雷达波段吸波效果突出, 已用于 坦克大型动力舱顶盖和外露部件。我国树脂基防热 复合材料在载人航天和星空探测等发展计划的推动 下, 研制出蜂窝增强低密度树脂基防热复合材料并 在载人返回舱上实现成功应用。

高性能碳纤维复合材料是复合材料产业的核心, 2016 年世界碳纤维复合材料年用量约为 $1.1 \times 10^{5} \mathrm{t}$, 市场总价值约为 200 亿美元, 市场发展前景广阔。 我国复合材料经过 30 多年的发展, 已建立起一批 复合材料构件研发平台和制造基地, 以促进复合材 料技术及产业水平的提升。

\section{四、高性能高分子复合材料发展面临的问题}

目前, 我国以碳纤维增强复合材料为代表的高 性能高分子复合材料尚处于发展阶段, 与国外先进 水平相比, 仍有较大差距。我国相关产品研发和产 业发展方向多是对标国外已有产品, 以跟踪仿制为 主, 产品的进口依赖程度较高, 产业化进程缓慢, 部分领域严重滞后于世界材料强国的发展速度。

\section{（一）碳纤维高端产品少, 低端产品价格贵, 对位 芳纶发展艰难}

我国高性能纤维各品种发展不均衡。对于高性 能无机纤维来说, 玻璃纤维进入产业化发展成熟期, 产品质量好且市场占有率高; 碳纤维处于产业化初 期, 产能不断提高, 但产量及市场占有率较低, 产 品质量的稳定性还有待提高; 芳纶纤维处于产业化 初期, 已具备一定的产能, 但产量较低, 产品质量 稳定性和市场占有率还有待进一步提高。

国产碳纤维生产成本居高不下, 用于航空、航 天等领域的高性能碳纤维与国外存在代差, 自主创 新能力亟待加强。同时, 我国碳纤维应用市场培育 迟缓, 风力发电、汽车等产业大规模应用尚未进行, 工业需求的拉动力较弱。现有碳纤维企业的产品多 集中于生产 $\mathrm{T} 300$ 级碳纤维, 存在一定的低水平无 序扩张, 再加上国外相关企业对我国中低档碳纤维 进行价格打压, 不利于碳纤维产业的成长, 难以形 成具有竞争力和可持续健康发展的产业。

在对位芳纶方面, 国外企业不断通过价格手段 对我国芳纶产品进行精准打压, 致使国内企业使用 
国产芳纶产品的积极性不高。同时, 国内芳纶生产 企业还面临着国外加强对芳纶单体 (对苯二甲酰氯) 出口控制的挑战。总之, 目前我国芳纶产业的成长 与发展困难重重。

\section{（二）树脂基材料的研发与应用水平存在差距}

树脂基体是纤维增强复合材料中最薄弱、最先 受到破坏的组分, 对复合材料整体性能的发挥起着 关键作用。我国在树脂基体方面存在的问题和差距 主要表现为: (1)研发力量薄弱, 研究主体以高校与 科研院所为主, 与企业开展复合材料的应用研究相 对脱节; (2)高品质、高纯度的环氧树脂、酚醛树脂 及改性高端产品规模化生产能力低; (3)针对高端领 域的先进复合材料要求, 树脂复配体系设计能力有 待加强; (4)高性能树脂基体产业化能力不足, 缺乏 满足低频段、全向隐身、透波、低密度、防隔热、 防弹等性能的产品。此外还需要加大新型超材料、 频率选择、石墨烯等新技术、新材料在结构吸波和 透波领域的应用力度。

\section{（三）树脂基复合材料设计、制造与应用水平低}

（1）我国复合材料的结构件设计以跟踪替代应 用为主, 自主设计应用能力较弱。目前, 根据国外 的实际应用统计, 主承力结构使用 $\mathrm{T} 300$ 级碳纤维 复合材料的减重效率可达 $25 \%$, 而我国减重效率则 相对较低, 多数不到 $20 \%$ 。

(2) 国产复合材料自动化成型工艺的应用比例 较低, 总体不足 $20 \%$, 主要局限于航空和航天等高 端领域, 民用复合材料仍以传统的手糊或手工铺贴 成型为主, 与国外的自动化制造水平存在明显差距。 工艺落后使复合材料性能离散大、成品率低、成本 高, 成为制约高性能复合材料发展的突出问题。

（3）复合材料制造关键装备技术水平薄弱, 以 进口引进为主、仿制为辅, 部分装备如热熔预浸机、 缠绕机、热压罐、热压机的设计制造以及复合材料 自动铺放设备、预浸料自动拉挤设备的研制虽取得 一定突破, 但在科研和生产中对进口装备的依赖程 度仍较高。

（4）高性能树脂基复合材料应用水平与发达 国家先进水平存在明显差距。我国研制的 ARJ 21 支线客机复合材料用量占比约为 $2 \%$, 正在研制的 C919 中型客机复合材料用量占比约为 $10 \%$, 而国
外最新研制的波音 787、空中客车 A350 等大型客 机复合材料用量占比则达到 $50 \%$ 以上。欧洲直升 机公司的 NH90 直升机复合材料达到了 95\%, 而国 内新型直升机 Z10 的复合材料用量占比仅为 $34 \%$ 。 高性能树脂基复合材料在大型客机、风力发电和汽 车等领域的大规模应用尚未破局, 复合材料产业尚 未形成规模。

（5）结构功能复合材料基础薄弱, 技术发展缺 乏综合设计能力。增强材料、树脂基体、功能填料 等原材料的研究单位分散, 低水平、同质化竞争严 重, 性能无法满足现有需求。新型超材料、频率选 择、石墨烯等新技术、新材料在结构吸波和透波领 域的应用取得一定进展, 但仍然处于理论设计和试 验验证阶段, 离实际工程应用要求仍然存在差距。 尽管我国在结构/吸波复合材料、结构 / 抗弹复合 材料、结构 / 防热复合材料方面的研究取得明显进 展, 但结构功能复合材料的发展仍存在顶层设计欠 缺、资源整合能力不够、重要领域空缺、跨学科综 合设计能力不足和技术共享不充分、低水平重复等 问题, 尚未形成通用化、系列化、标准化的材料体 系, 缺少支撑未来技术发展的高性能产品。

\section{五、我国高性能高分子复合材料的发展目标 与发展建议}

\section{(一) 发展目标}

1. 面向 2025 年的发展目标

面向 2025 年的发展目标为: 完成国产碳纤维 品种系列化、工艺多元化、产能规模化, 高强、高 强中模和高模高强碳纤维主要产品满足应用需求, 具备产业竞争力; 突破大规模一体化对位芳纶生产 制备技术, 建成万吨级生产线; 建立基于高强中模 碳纤维的第二代先进复合材料规模化制备与应用平 台, 实现在大飞机、载人航天等重大工程中的应用, 并在武器装备方面得到全面替代应用, 达到世界先 进水平。

重点发展方向包括: (1)加强国产碳纤维高性 能、低成本制备技术研发, 突破 T1100 级别碳纤维 的国产化技术, 开展 M55J 级高模高强碳纤维稳定 工程化技术研究以及 $\mathrm{M} 65 \mathrm{~J}$ 级碳纤维制备关键技术 研究, 产品实现国防型号应用。突破具有高强高模 高㓞高延伸、压缩与拉伸性能均衡发展特征的国产 
碳纤维制备技术; 开展千吨级及以上规模的 T300、 $\mathrm{T} 700$ 和 T800 级碳纤维低成本产业化制备技术研 究, 开展高速干喷湿纺纺丝工艺系统技术集成研究; 突破 $48 \mathrm{~K}$ 以上大丝束碳纤维批量生产关键技术。 (2)突破大规模一体化对位芳纶生产制备技术, 建成 万吨级生产线。(3)开展碳纤维复合材料设计与在 航空和航天等领域的应用技术研究, 包括与国产 $\mathrm{T} 800$ 级碳纤维匹配的高韧性预浸料用树脂设计改 进及规模化合成技术， RTM 树脂配方设计及规模 化合成技术，国产高强中模碳纤维预浸料质量与性 能一致性控制技术，RTM 复合材料增韧技术，复 合材料快节拍制造技术研究，国产高强中模碳纤维 复合材料适航验证技术等。(4)开展高强高模高㓞且 拉压平衡碳纤维增强树脂基复合材料技术研究, 研 发以全面替代高性能铝合金为目标的第三代先进复 合材料。(5)实现国产低成本高性能高分子复合材料 在建筑、风电叶片、输电缆线、汽车和轨道交通等 领域的应用。

2. 面向 2035 年的发展目标

面向 2035 年的发展目标为: 通过自主创新, 建立满足我国应用需求的高性能增强体纤维技术与 产品系列, 形成国防用国产高性能纤维及其复合材 料的持续自主保障能力。研发出国家优势产业、战 略产业以及新型武器装备所必需的新型高性能纤维 复合材料, 通过使用环境下的规模化验证, 提高产 品的性能和市场竞争力。实现国产高性能高分子复 合材料产业化及推广应用, 使我国复合材料技术达 到世界同步发展水平并逐步实现全面超越和引领国 际发展水平。

重点发展方向包括：(1)实现 M55J、M65J、T1100 等级别的高性能碳纤维的工程化制备, 满足国防军 工与国民经济发展需求。(2)根据实际服役环境对材 料性能的需求, 实现高性能新型树脂基体的结构设 计及高分子复合材料超微界面控制, 实现复合材料 快速成型新方法、超大尺寸复合材料一体化成型等 新型技术的开发。(3)建立起国产高分子复合材料产 业技术创新体系, 满足国防及国民经济重大领域的 需求。

\section{（二）对策建议}

1. 注重自主创新, 促进产业可持续发展 高性能高分子复合材料的发展，应坚持以重大
领域应用为导向、以科学认知提升为基础、以关键 技术突破为中心、以产业创新为目标, 既瞄准国家 重大工程急需, 又兼顾前沿科学技术发展, 消除制 备与应用脱节的现象, 快速提高产业技术成熟度, 建立严格科学合理的运行机制。

2. 坚持以高端装备需求为牵引进行技术突破, 通过民用需求的规模化推动产业发展, 实现良性 循环

在高性能高分子复合材料高性能化、低成本 化发展趋势的带动下, 以航空和航天等国家安全 领域的高端产品需求为导向, 不断进行技术突破, 提供关键战略基础材料保障, 同时在以汽车、风 力发电、压力容器等为代表的民用领域扩大应用, 提升企业自身造血功能, 实现国产高性能高分子 复合材料产业的健康可持续性发展, 满足国家安 全、国防现代化建设、国民经济和国家中长期重 大工程的需要。

3. 重视高性能高分子复合材料产业链建设, 建 立碳纤维复合材料高效低成本应用技术体系

加强投入及引导, 从高性能纤维增强体 - 复合 材料 - 市场应用进行系统布局和技术攻关，夯实发 展基础。重点培育技术与装备硬实力, 建设复合材 料设计 - 制造 - 应用为一体的完整产业技术链条。 推动高性能高分子复合材料在能源、交通运输、建 筑工程等重点民用产业的发展, 形成高性能纤维增 强体研发与生产、高性能树脂研发生产和复合材料 制备及应用的完备产业链。

4. 加强人才培养, 尊重知识产权及标准化建设, 支持产业创新中心建设

建议加强相关交叉专业的融合, 扩大人才培养 规模并加强跨专业复合型人才培养; 在重点企业建 立企业技术中心和重点实验室等高水平开放研究平 台, 切实加强和提升企业的工艺技术水平; 重视检 测标准、工艺标准及产品质量标准规范的建立; 尊 重知识产权, 建立合理有序的人才流动机制, 为我 国高性能高分子复合材料技术产业持续健康发展提 供自主创新源动力。

\section{参考文献}

[1] 刘瑞刚, 徐坚. 国产高性能聚丙烯腈基碳纤维制备技术研究进 展 [J]. 科技导报, 2018, 36(19): 32-42.

Liu R G, Xu J. Recent progress in high performance PAN based carbon fibers [J]. Science \& Technology Review, 2018, 36(19): 
32-42.

[2] 徐樑华. 高性能PAN基碳纤维国产化进展及发展趋势. [J]. 中国 材料进展, 2012, 31(10): 7-14.

$\mathrm{Xu}$ L H. Development and trends of PAN-based high performance carbon fiber in China [J]. Materials China, 2012, 31(10): 7-14.

[3] 万雷, 吴文静, 吕佳滨, 等. 我国对位芳纶产业链发展现状及展 望 [J]. 高科技纤维与应用, 2019, 44(3): 21-26.

Wan L, Wu W J, Lyu J B, et.al. The current situation and prospect of para-aramid industry chain in China [J]. Hi-Tech Fiber \& Application, 2019, 44(3): 21-26.
[4] 王雷, 卢家骐, 郑莉, 等. 耐高温硼酚醛生产研究 [J]. 玻璃钢 / 复 合材料, 2009, 26(2): 68-71.

Wang L, Lu J Q, Zheng L, et al. Study on the high temperature -resistant boron-phenolic resin [J]. Fiber Reinforced Plastics / Composites, 2009, 26(2): 68-71.

[5] 邢丽英, 包建文, 礼嵩明, 等. 先进树脂基复合材料发展现状和 面临的挑战 [J]. 复合材料学报, 2016, 33(7): 1327-1338.

Xing L Y, Bao J W, Li S M, et al. Development status and facing challenge of advanced polymer matrix composites [J]. Acta Materiae Compositae Sinca, 2016, 33(7): 1327-1338. 